J. Dairy Sci. 95:6677-6686

http://dx.doi.org/10.3168/jds.2012-5605

(C) American Dairy Science Association ${ }^{\circledR}, 2012$.

\title{
An alkalinizing oral rehydration solution containing lecithin-coated citrus fiber is superior to a nonalkalinizing solution in treating 360 calves with naturally acquired diarrhea
}

\author{
G. M. Goodell, ${ }^{\star}$ J. Campbell,† L. Hoejvang-Nielsen,‡ W. Stansen, $§$ and P. D. Constable\# ${ }^{1}$ \\ *The Dairy Authority, Greeley, CO 80634 \\ †Boehringer Ingelheim Vetmedica, St. Joseph, MO 64506 \\ $\ddagger$ ßBoehringer Ingelheim Vetmedica, DK-2100 Copenhagen, Denmark \\ §Boehringer Ingelheim, 55216 Ingelheim, Germany \\ \#Department of Veterinary Clinical Sciences, School of Veterinary Medicine, Purdue University, IN 47907
}

\begin{abstract}
The aim of this field study was to compare the efficacy and cost of 2 commercially available oral rehydration therapy (ORT) solutions in treating dairy calves with naturally acquired diarrhea. A total of 1,349 newborn Holstein-Friesian calves were prospectively enrolled in the study. Calves were housed in individual hutches and fed a mixture of pasteurized hospital milk and an allmilk protein milk replacer twice per day. Calves were monitored twice each day from d 2 of life until $30 \mathrm{~d}$ of age for the presence or absence of diarrhea, and were assigned a fecal score and a hydration score at each examination. Calves that developed mild to severe diarrhea that did not need intravenous fluids and did not have clinical evidence of concurrent disease $(\mathrm{n}=360)$ were assigned randomly to receive 1 of 2 commercial ORT solutions: a hypertonic alkalinizing ORT containing lecithin-coated citrus fibers (Diaque, group D, n = 180; Boehringer Ingelheim, Ingelheim, Germany), and an isotonic nonalkalinizing ORT (RE-SORB, group $\mathrm{R}, \mathrm{n}=180$; Pfizer Animal Health, New York, NY) for 2 to $8 \mathrm{~d}$; the duration of treatment depended on whether diarrhea was still present. No significant differences were observed in mortality rates or treatment failure rates between the 2 treatment groups. Fecal consistency returned to normal more quickly in group $\mathrm{D}$ calves than in group $\mathrm{R}$ calves; consequently, group $\mathrm{D}$ calves were treated for $1 \mathrm{~d}$ less than were group $\mathrm{R}$ calves. The increase in body weight after $4 \mathrm{~d}$ of treatment was larger in group $\mathrm{D}$ than in group $\mathrm{R}$. The average daily gain from birth to weaning in calves that did not develop concurrent disease (such as pneumonia) during the study period tended to be higher in group D
\end{abstract}

Received April 9, 2012.

Accepted July 5, 2012.

${ }^{1}$ Corresponding author: constabl@purdue.edu calves $(0.53 \pm 0.11 \mathrm{~kg} / \mathrm{d})$ than in group $\mathrm{R}$ calves $(0.51$ $\pm 0.09 \mathrm{~kg} / \mathrm{d})$. The smaller number of treatments at a lower cost per treatment produced a cost advantage of $\$ 4.82$ per treated calf in group D calves compared with group R calves. Our findings support the concept that milk should continue to be fed to diarrheic calves that are being administered an ORT solution in order to maintain growth.

Key words: calf diarrhea, oral electrolyte rehydration solution, strong ion difference

\section{INTRODUCTION}

Neonatal calf diarrhea is a major source of economic loss to the cattle industry and is the leading cause of dairy calf mortality (Svensson et al., 2003; USDA, 2010) and an important cause of beef morbidity (Busato et al., 1997) in most countries. The United States Department of Agriculture estimates that $7.8 \%$ of dairy heifers die between d 2 of life and weaning, with the majority of deaths attributable to diarrhea or other digestive problems (USDA, 2010). Calf diarrhea has the highest annual costs for treatment and control of any disease in US dairy cattle, exceeding the treatment and control costs for mastitis, respiratory disease, or lameness (Weigler et al., 1990). Diarrhea in neonatal calves can lead to dehydration, hyponatremia, hyper D-lactatemia, strong ion (metabolic) acidosis, hyperkalemia, and impaired cardiovascular and renal function (Constable, 2003; Constable et al., 2005; Sen et al., 2009). Oral rehydration therapy (ORT) solutions provide a practical and inexpensive method for treating mild to moderate strong ion (metabolic) acidosis and dehydration in neonatal calves with diarrhea; however, the energy content in ORT solutions is inadequate to meet the needs of the calf, even when high-glucose ORT solutions are fed (Constable et al., 2001). Uncertainty remains about the optimal electrolyte concentrations, type of buffer, and type and amount of energy source, 
as well as the $\mathrm{pH}$ and osmolality of the ORT solution (Constable et al., 2001; Constable, 2003; Smith, 2009). Studies in the late 1970s and 1980s demonstrated that milk withdrawal and concurrent administration of an ORT solution decreased mortality in calves with diarrhea (Bywater, 1977, 1980; Booth and Naylor 1987). Continued milk feeding to calves showing mild to moderate signs of diarrhea does not exacerbate diarrhea (Naylor et al., 1990) and is recommended to maintain growth and support the repair of damaged intestinal mucosa (Heath et al., 1989; Garthwaite et al., 1994).

Many dairy producers feed ORT solutions to diarrheic calves between milk feedings or at the time of milk feeding. In the past, ORT solutions were not mixed with milk because of concerns about changes in intestinal morphology and bacterial flora leading to fermentation of undigested and unabsorbed nutrients, inhibition of chymosin clot formation in the abomasum, and decreased abomasal emptying rate because of increased osmolality of the ORT (Heath et al., 1989; Svensson et al., 2003; Sen et al., 2006; Nouri and Constable, 2006; Bachmann et al., 2009; Constable et al., 2009). These concerns led to recommendations that milk should be withdrawn from feeding for the first 2 d of treatment (Svensson et al., 2003) and that ORT solutions should be administered at least $1 \mathrm{~h}$ before or after the milk feeding. Although the separate feeding of ORT solutions has proven effective in treating calves for diarrhea, the added labor to visit diarrheic calves 1 to 2 additional times each day has increased the expense and reduced treatment compliance. Two ORT solutions, Diaque (Boehringer Ingelheim, Ingelheim, Germany) and RE-SORB (Pfizer Animal Health, New York, NY), are labeled to be fed directly with the milk of calves during their normal feeding, thereby eliminating the need for extra visits to calves with diarrhea. The 2 ORT solutions differ in their label recommendations in that Diaque can be fed immediately with milk, whereas milk must be withheld for the first 4 feedings $(48 \mathrm{~h})$ that RE-SORB is fed; after $48 \mathrm{~h}, 0.95 \mathrm{~L}$ of RE-SORB can be mixed with $0.95 \mathrm{~L}$ of milk or milk replacer, and the 1.89-L mixture can be fed for the next 4 feedings (feedings 5 through 8 ). The main objective of this study was therefore to compare the effectiveness of 2 commercially available ORT solutions for the initial treatment of dairy calves with diarrhea. A secondary purpose was to perform a partial budget analysis of the 2 treatments. We hypothesized that continued milk feeding in calves with diarrhea that were administered an ORT solution would result in a shorter treatment duration, lower treatment costs, and increased BW, relative to withholding milk for the first 4 feedings.

\section{MATERIALS AND METHODS}

\section{Animals and Management}

The study was conducted at a 12,000-cow dairy in northern Colorado. Holstein-Friesian calves were processed within $5 \mathrm{~h}$ of birth in the maternity area of the dairy. Processing consisted of dipping the navels with $7 \%$ tincture of iodine, ear tagging, collecting a skin sample (ear notch) for antigen capture ELISA for bovine viral diarrhea virus, and measuring BW. Calves were fed $3.89 \mathrm{~L}$ of colostrum at processing and an additional $1.89 \mathrm{~L}$ of colostrum at a second feeding.

Processed calves were transported one-half mile from the maternity area to the calf ranch twice each day. Calves were housed individually at the calf ranch in hutches with panels that permitted nose-to-nose contact with calves in adjacent hutches. Calves were fed twice a day with a fixed volume of $1.89 \mathrm{~L}$ of a mixture of pasteurized nonsalable milk and milk replacer in a bottle with a nipple. Milk was pasteurized at $71.1^{\circ} \mathrm{C}$ for 30 min by using a vat pasteurizer. The milk mixture consisted of approximately $60 \%$ pasteurized nonsalable milk (estimated as $27 \%$ fat and $25 \%$ protein on a DM basis), $40 \%$ dry all-milk protein milk replacer (20\% fat and $20 \%$ protein on a DM basis, $0.567 \mathrm{~kg}$ of milk replacer powder per $3.785 \mathrm{~L}$ of water; IBA Instant Milk Replacer, IBA Inc., Milbury MA), and water. A commercial calf starter ration $(18 \% \mathrm{CP}$, as-fed basis) was offered at 1 wk of age, but consumption was not monitored.

A jugular venous blood sample was collected from calves at approximately $48 \mathrm{~h}$ of age for determination of serum total protein concentration by refractometry (Jor-Vet J351 Clinical Refractometer; Jorgensen Laboratories, Loveland CO). Transfer of passive immunity was considered failed if serum total protein concentration was $<5.0 \mathrm{~g} / \mathrm{dL}$ (Tyler et al., 1996). Calves were vaccinated and treated according to standard protocols for the dairy. Calves were weighed when weaned at approximately 8 wk of age.

\section{Enrollment and Treatment}

An observer walked through the calf ranch twice each day with the calf ranch staff and examined all calves $<30 \mathrm{~d}$ of age. The observer identified calves that had uncomplicated diarrhea [defined as diarrhea but the absence of fever (rectal temperature $>39.7^{\circ} \mathrm{C}$ or other systemic signs of illness) and notified the investigator of the calf's ear tag and location. Calves were initially assigned a fecal score of 0 to 4 ( $0=$ normal; $1=$ normal consistency but may include specks of fresh blood or 
meconium; $2=$ mild diarrhea; $3=$ moderate diarrhea; $4=$ severe diarrhea; fecal scores of $0,2,3$, and 4 reflect a median percentage of DM of 21, 16, 10, and 6, respectively; Bellosa et al., 2011). Diarrhea was defined as voiding of fecal material that splashed when hitting the ground. Calves with a fecal score of 1 to 4 were enrolled into the study; however, calves with severe dehydration, depression, and diarrhea that needed intravenous fluid treatment were excluded from the study. The rectal temperature and BW of calves were recorded on enrollment.

Enrolled calves were assigned randomly, using a random number generator (Minitab 16; Minitab Inc., State College PA), to treatment with either Diaque (group D) or RE-SORB (group R) as per label directions for the first $4 \mathrm{~d}$ of treatment. Diaque is a nutritional supplement containing hydrophobic lecithin-coated citrus fibers that provide a source of energy and electrolytes for calves. RE-SORB is an oral hydration electrolyte product that is indicated for use in the control of dehydration associated with diarrhea (scours) in calves. RE-SORB was selected as a comparison ORT treatment because it is the only ORT solution in the United States with a label claim of controlling dehydration in scouring calves. For comparison, all other ORT solutions in the United States are sold as feed supplements, for which no medical claims can be made.

Treatments were administered by the investigator. Calves in group D received $100 \mathrm{~g}$ of Diaque (1 packet or 2 scoops) mixed into $1.89 \mathrm{~L}$ of a warm milk mixture orally upon enrollment and twice daily for at least $2 \mathrm{~d}$ and thereafter while diarrhea persisted (fecal score $>1$ ) for a maximum of $8 \mathrm{~d}$ of treatment. Calves in group $\mathrm{R}$ received 1 packet $(64 \mathrm{~g})$ of RE-SORB mixed into $1.89 \mathrm{~L}$ of warm water orally upon enrollment and twice daily for $2 \mathrm{~d}$. No milk or milk replacer was fed to calves in group $\mathrm{R}$ for the first 4 routine feedings ( 1 and 2 ). If diarrhea persisted in group $\mathrm{R}$ calves after the first 4 feedings, $0.95 \mathrm{~L}$ of milk mixture was mixed with 0.95 L of RE-SORB and the resultant 1.89-L solution was fed twice each day to all group $\mathrm{R}$ calves while diarrhea persisted. The label directions for RE-SORB indicated that calves should be fed as normal from d 5 onward and that the ORT solution should not be administered beyond $\mathrm{d} 4$ without the addition of milk or milk replacer. If diarrhea persisted in group $\mathrm{R}$ calves from $\mathrm{d}$ 5 to 8 , the calves were fed the same ORT solution and milk mixture as on d 3 and 4 to follow label directions and provide a suitable comparison group for calves fed Diaque. The calculated ORT solution concentrations as fed to calves in this study are summarized in Table 1. The calculated concentrations have been shown to approximate the actual concentrations when Diaque is mixed in fresh cow's milk (Constable et al., 2009).
In addition to the randomly assigned treatment, calves received parenteral ceftiofur $(2.2 \mathrm{mg} / \mathrm{kg}$ of BW, i.m. or s.c.) and activated charcoal (40 g in a 1.89-L solution, as fed) daily for $3 \mathrm{~d}$ per the routine treatment protocol of the dairy. Treatment was discontinued when the stool returned to normal after d 2 in group $\mathrm{D}$ and after $\mathrm{d} 4$ in group $\mathrm{R}$ or when a calf reached d 8 of treatment; calves in the latter category were designated as treatment failures, removed from the study, and treated according to standard protocols for the dairy. Calves that developed a concurrent disease (e.g., omphalophlebitis or pneumonia) after they were assigned to treatment were removed from the study and treated according to standard protocols for the dairy.

\section{Assessment of Treated Calves}

The observer remained masked to treatment group and accompanied the calf ranch staff twice daily to make observations on all enrolled calves. Fecal consistency and hydration status were scored twice daily by the observer until the calf met the stated criteria for stopping treatment. The amount suckled within $10 \mathrm{~min}$ was estimated as $0,25,50,75$, or $100 \%$ of the allotted volume.

Diarrhea, dehydration, and consumption of the test solution were monitored for all enrolled calves. Calves were assigned a hydration score of 0 to 3 , with $0=$ normal; $1=$ eyes beginning to sink and skin turgor decreased; $2=$ eyes sunken and mucous membranes tacky; or $3=$ eyes deeply sunken and skin tent $>5$ s. Fecal scoring and hydration scoring were done immediately before feeding and was conducted by the observer. Consumption of the test solution by suckling was evaluated by the investigator at every feeding, and calves that were unable to suckle their allotted volume within 10 min received the remainder of the fluid by oroesophageal intubation.

\section{Data Analysis}

The primary outcome variables of interest were mortality rate, treatment failure rate, days of treatment (number of days a calf received treatment), fecal score, hydration score, and ADG. Average daily gain was calculated by subtracting the birth weight from the calf's weaning weight and dividing by the number of days between BW measurements. Data for determination of ADG were audited to exclude calves that had an adverse health event other than diarrhea. This was because calves with disease events in addition to diarrhea, such as omphalophlebitis or pneumonia, could negatively influence ADG calculations and thereby bias treatment outcomes. A partial budget analysis was 
Table 1. Calculated components of 2 oral rehydration therapy (ORT) solutions containing bicarbonate, acetate, citrate, and glycine (fed to group D calves) or citrate and glycine (fed to group R calves) in water or cow's milk

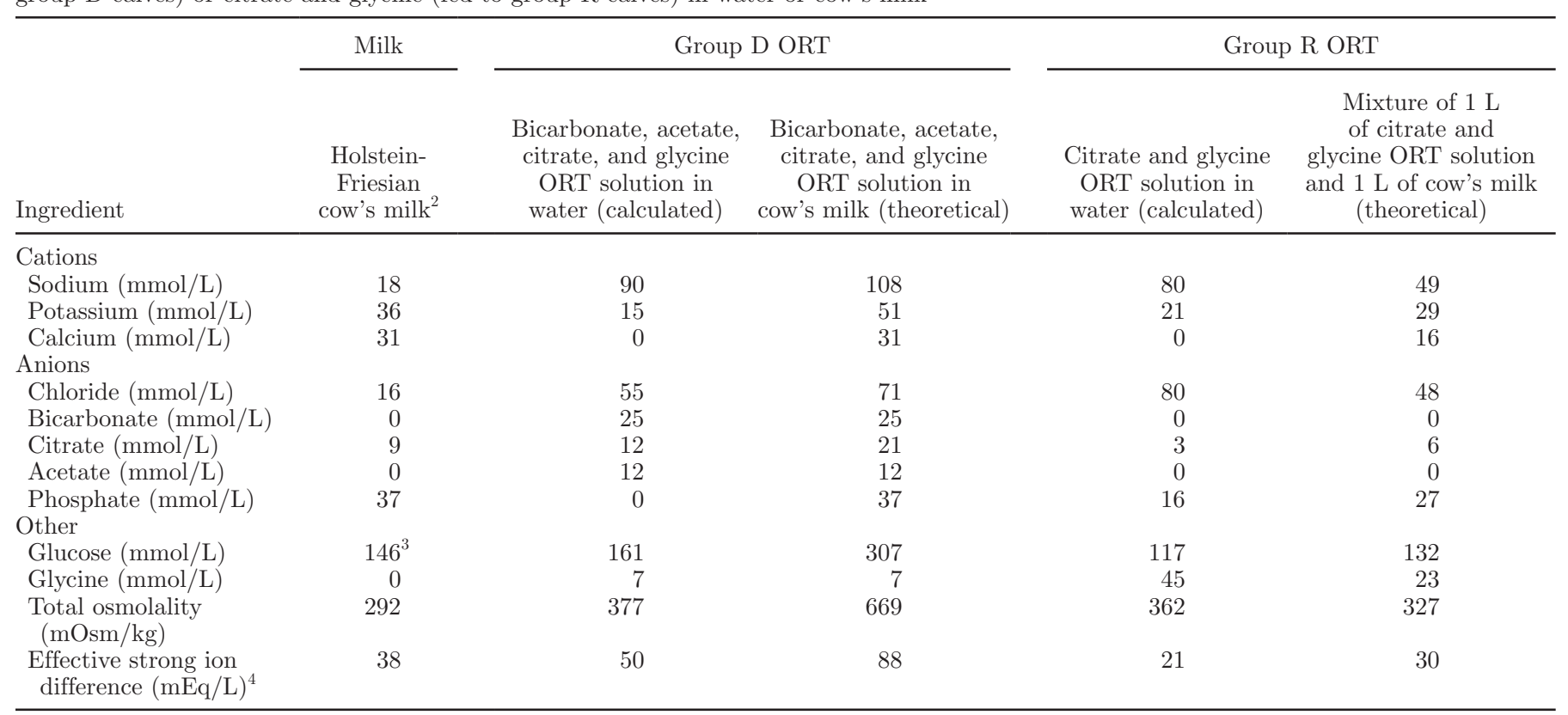

${ }^{1}$ Data are expressed as mean values. Adapted from Constable et al. (2009).

${ }^{2}$ From Davies and White (1959); Cerbulis and Farrell (1976).

${ }^{3}$ Maximum theoretical glucose concentration derived from the breakdown of the disaccharide lactose (146 mmol/L) into glucose and galactose.

${ }^{4}$ Effective strong ion difference $=\left[\mathrm{Na}^{+}\right]+\left[\mathrm{K}^{+}\right]-\left[\mathrm{Cl}^{-}\right]$.

calculated for calves in both treatments by using costs for the dairy.

\section{Statistical Analysis}

Data were expressed as mean \pm standard deviation, and $P<0.05$ was considered significant. Data were analyzed using SAS statistical software (PROC GLM, PROC FREQUENCY, PROC LIFETEST, PROC PHREG, SAS 9.2; SAS Institute Inc., Cary, NC). Continuous variables were compared using ANOVA. Categorical variables were compared using $\chi^{2}$ analysis. Fisher's exact test was used whenever the expected count in more than $20 \%$ of the cells was $<5$. The product-limit Kaplan-Meier method was used to determine and compare the time for the proportion of calves with diarrhea in groups $\mathrm{D}$ and $\mathrm{R}$ to decrease by $50 \%$. Data were censored if diarrhea was still present on $\mathrm{d} 8$ of treatment. The Kaplan-Meier method was also used to determine and compare the time for the proportion of all calves with diarrhea enrolled in groups $\mathrm{D}$ and $\mathrm{R}$ with serum total protein concentration $<5.0$ or $\geq 5.0 \mathrm{~g} / \mathrm{dL}$ on $\mathrm{d} 2$ of life to decrease by $25 \%$. This percentage was selected because the 2 groups did not decrease by $50 \%$ by d 8 . Wilcoxon statistics were used to evaluate equality over strata. Plots of $\ln [-\ln ($ diarrhea present)] against the $\ln$ (days) were used to evaluate the proportionality of the distributions. Cox proportional hazard ratios were used to compare the effect of the 2 ORT solutions and the transfer of passive immunity status on the presence of diarrhea. The Cox approximation to proportional hazards analysis was used because the time-scale was discrete. The assumption of proportional hazards was investigated by examining the log-cumulative hazard plot and deviance residual plots (Collett, 2003).

\section{RESULTS}

\section{Calves}

A total of 1,349 calves reached $2 \mathrm{~d}$ of age during the study period and were eligible for entry into the study (1 calf tested positive for bovine viral diarrhea virus and was removed from the farm). Of these 1,349 calves, 650 had a fever or systemic signs of diseases other than diarrhea, such as respiratory disease or omphalophlebitis; 468 had abnormal feces (diarrhea score of 1, 2, 3 , or 4) without fever or systemic signs of disease and were therefore enrolled in the study; and 128 calves remained healthy for the first $30 \mathrm{~d}$ of life (group C). Of the 468 calves enrolled in the study, 231 were initially assigned to group D and 237 were assigned to group $\mathrm{R}$. Subsequent review of the records indicated that the investigator assigned a maximum fecal score of 0 or 
1 to 108 of the 468 calves on the day of enrollment. Because we were interested in determining the effects of the ORT solution in calves with diarrhea, data analysis was confined to 180 calves in group D and 180 calves in group $\mathrm{R}$ that had a maximum fecal score of 2,3 , or 4 (mild, moderate, or severe diarrhea) as assigned by the investigator on the day of enrollment.

The mean birth weights for calves in group D and group $\mathrm{R}$ were similar ( $P=0.77$; Table 2$)$. It is interesting that the birth weight for calves in group $\mathrm{C}$ was significantly greater than those for calves in group $\mathrm{D}(P$ $=0.0004)$ and group $\mathrm{R}(P=0.0013)$.

\section{Transfer of Passive Immunity, Sex, Age, and Rectal Temperature on Enrollment}

Minor differences were observed in the extent of transfer of passive immunity between the 2 groups, as indicated by differences in mean serum total protein concentration when calves were $2 \mathrm{~d}$ of age (Table 2). Serum total protein concentration was higher in group $\mathrm{D}$ calves than in group $\mathrm{R}$ calves $(P=0.0080)$, and the proportion of calves with failure of transfer of passive immunity in group $\mathrm{R}$ was greater $(P=0.0028)$ than the proportion in group $\mathrm{D}$ (Table 3 ), as assessed by serum total protein concentration $<5.0 \mathrm{~g} / \mathrm{dL}$.

The proportion of heifer calves in group $\mathrm{D}$ was similar to that in group $\mathrm{R}(P=0.96$; Table 3$)$. Age and rectal temperature were similar for both groups on enrollment (Table 2).

\section{Fecal Score, Dehydration Score, and Appetite Score on Enrollment}

Most calves in both groups were dehydrated and had a decreased appetite on enrollment. The proportion of calves with fecal scores of 2,3 , or 4 at enrollment were similar for both groups $(P=0.83$; Table 3$)$. The proportion of calves with dehydration scores of $0,1,2$, and 3 were similar for both groups at enrollment $(P=$ 0.086). Likewise, the proportion of calves that suckled $0,25,50,75$, or $100 \%$ of their allotted solution within 10 min were similar for both groups at enrollment $(P$ $=0.46)$.

\section{Mortality Rate and Treatment Failure Rate}

The all-cause mortality rate from $2 \mathrm{~d}$ of age to weaning for all calves was $6.1 \%(82 / 1,349)$. Cause of death was not determined. A total of $13(3.6 \%)$ of the 360 enrolled calves died by weaning, $7 / 180(3.9 \%)$ in group $\mathrm{D}$ and $6 / 180(3.3 \%)$ in group $\mathrm{R}$. No difference $(P=$ 1.00) was observed in the mortality rate between the 2 groups. Only 1 calf died during treatment with an

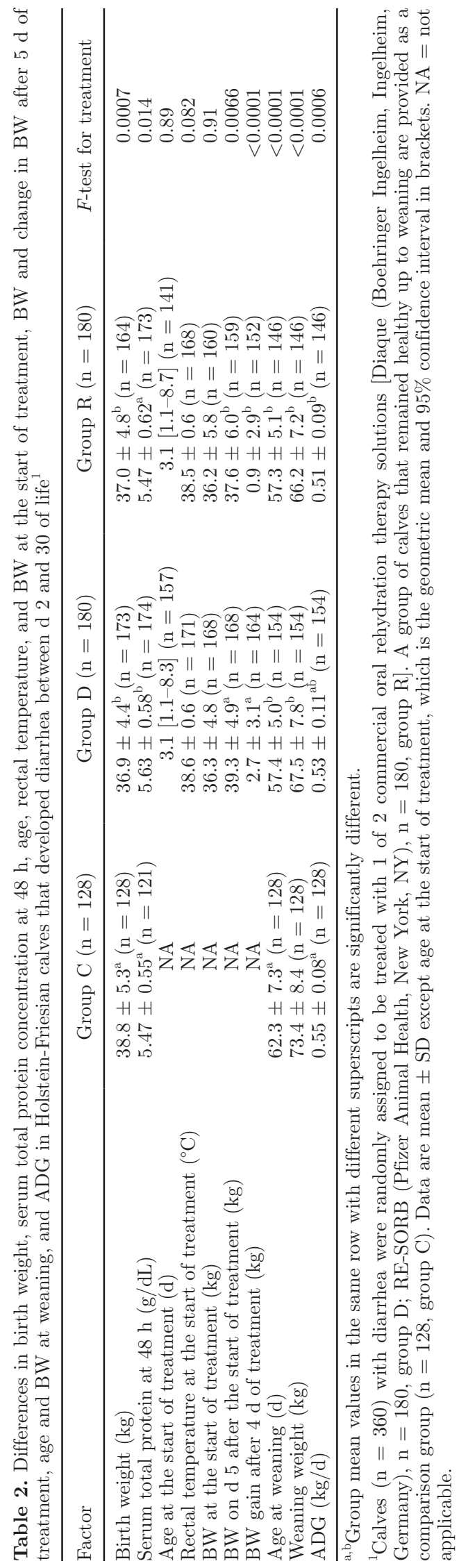

Journal of Dairy Science Vol. 95 No. 11, 2012 
Table 3. Maximal fecal scores, dehydration scores, and appetite scores on the day of enrollment, as well as sex and adequacy of transfer of passive immunity for 360 Holstein-Friesian calves that developed diarrhea between d 2 and 30 of life ${ }^{1}$

\begin{tabular}{|c|c|c|c|}
\hline Factor & $\begin{array}{c}\text { Group D } \\
(\mathrm{n}=180)\end{array}$ & $\begin{array}{c}\text { Group R } \\
(\mathrm{n}=180)\end{array}$ & $P$-value \\
\hline Fecal score on enrollment ( 0 to 4 ) & & & 0.83 \\
\hline 2 & 95 & 90 & \\
\hline 3 & 51 & 52 & \\
\hline 4 & 34 & 38 & \\
\hline Dehydration score on enrollment (0 to 3 ) & & & 0.086 \\
\hline 0 & 67 & 68 & \\
\hline 1 & 82 & 97 & \\
\hline 2 & 27 & 13 & \\
\hline 3 & 3 & 2 & \\
\hline Percentage of allotted volume suckled (0 to 100\%) & & & 0.46 \\
\hline 0 & 37 & 35 & \\
\hline 25 & 15 & 17 & \\
\hline 50 & 34 & 23 & \\
\hline 75 & 20 & 17 & \\
\hline 100 & 71 & 84 & \\
\hline Sex of the calf & & & 0.96 \\
\hline Female & 155 & 158 & \\
\hline Male & 18 & 18 & \\
\hline Transfer of passive immunity & & & 0.0028 \\
\hline Failure (total protein $<5.0 \mathrm{~g} / \mathrm{dL}$ ) & 19 & 41 & \\
\hline Adequate (total protein $\geq 5.0 \mathrm{~g} / \mathrm{dL}$ ) & 161 & 139 & \\
\hline
\end{tabular}

${ }^{1}$ Calves with diarrhea were randomly assigned to treatment with 1 of 2 commercial oral rehydration therapy solutions [Diaque (Boehringer Ingelheim, Ingelheim, Germany), $\mathrm{n}=180$, group D; RE-SORB (Pfizer Animal Health, New York, NY), $\mathrm{n}=180$, group R]. Numbers do not sum to 180 per group for all factors because of missing data.

ORT solution, and this was a calf in group R. Both appetite and hydration status improved over time, with no marked differences between groups.

Any calf whose diarrhea had not resolved by d 8 of treatment was determined to be a treatment failure. Time to event analysis (Figure 1) indicated that the treatment failure rate for calves in group D was $22 \%$ (n $=40)$, which was similar to that in group $\mathrm{R}(28 \%, \mathrm{n}=$ 50). Calves in group D had a normal stool (fecal score 0 or 1) by a median of $7.0 \mathrm{~d}$ of treatment ( $95 \%$ confidence interval, 6.5 to $8.0 \mathrm{~d})$. This was significantly shorter $\left(\chi^{2}\right.$ $=6.92, P=0.0085$, Wilcoxon test of equality of strata) than the time taken in group R (median, $8.0 \mathrm{~d}$ of treatment, $95 \%$ confidence interval, 7.5 to $8.0 \mathrm{~d}$ ).

Time to event analysis indicated that $25 \%$ of the calves with failure of transfer of passive immunity [(total protein) $<5.0 \mathrm{~g} / \mathrm{dL}]$ had a normal stool (fecal score 0 to 1 ) by a median of $7.0 \mathrm{~d}$ of treatment ( $95 \%$ confidence interval, 5.0 to 8.0 d; Figure 2). This was significantly longer $\left(\chi^{2}=9.96, P=0.0016\right.$, Wilcoxon test of equality of strata) than the time taken for $25 \%$ of the calves with adequate transfer of passive immunity to have a normal stool (median of $5.5 \mathrm{~d}$ of treatment, $95 \%$ confidence interval, 4.5 to $6.0 \mathrm{~d}$ ).

The Cox proportional hazards model using ORT type (group D, group R) and serum total protein concentration in grams per deciliter on $\mathrm{d} 2$ of life indicated that calves in group D were more likely to have a normal stool (hazard ratio, 1.36; 95\% Wald confidence limits, 1.04 to $1.78 ; P=0.048$ ) than calves in group $\mathrm{R}$. For comparison, each $1 \mathrm{~g} / \mathrm{dL}$ increase in total protein concentration was numerically, but not statistically, associated with an increased likelihood of a normal stool (hazard ratio, 1.06; 95\% Wald confidence limits, 0.85 to $1.32 ; P=0.59)$.

\section{Changes in BW}

No difference was observed in the weight at enrollment in the study between calves in group D and group $\mathrm{R}$ (Table 2). A significant difference was observed in $\mathrm{BW}$ and BW gain on the fifth day of treatment, with group D calves being heavier and gaining more weight. Group D calves had a similar weight $(P=0.14)$ as group $\mathrm{R}$ calves at weaning.

\section{Weaning Age and ADG}

The average age at weaning was similar for calves in group D and group R, but was significantly longer for calves in group C (Table 2). Average daily gain for calves in group D was less than that in control calves $(P=0.036)$. In comparison, ADG in group $\mathrm{R}$ was much lower than that of control calves $(P<0.0001)$ but was similar to that in group $\mathrm{D}(P=0.059)$. 


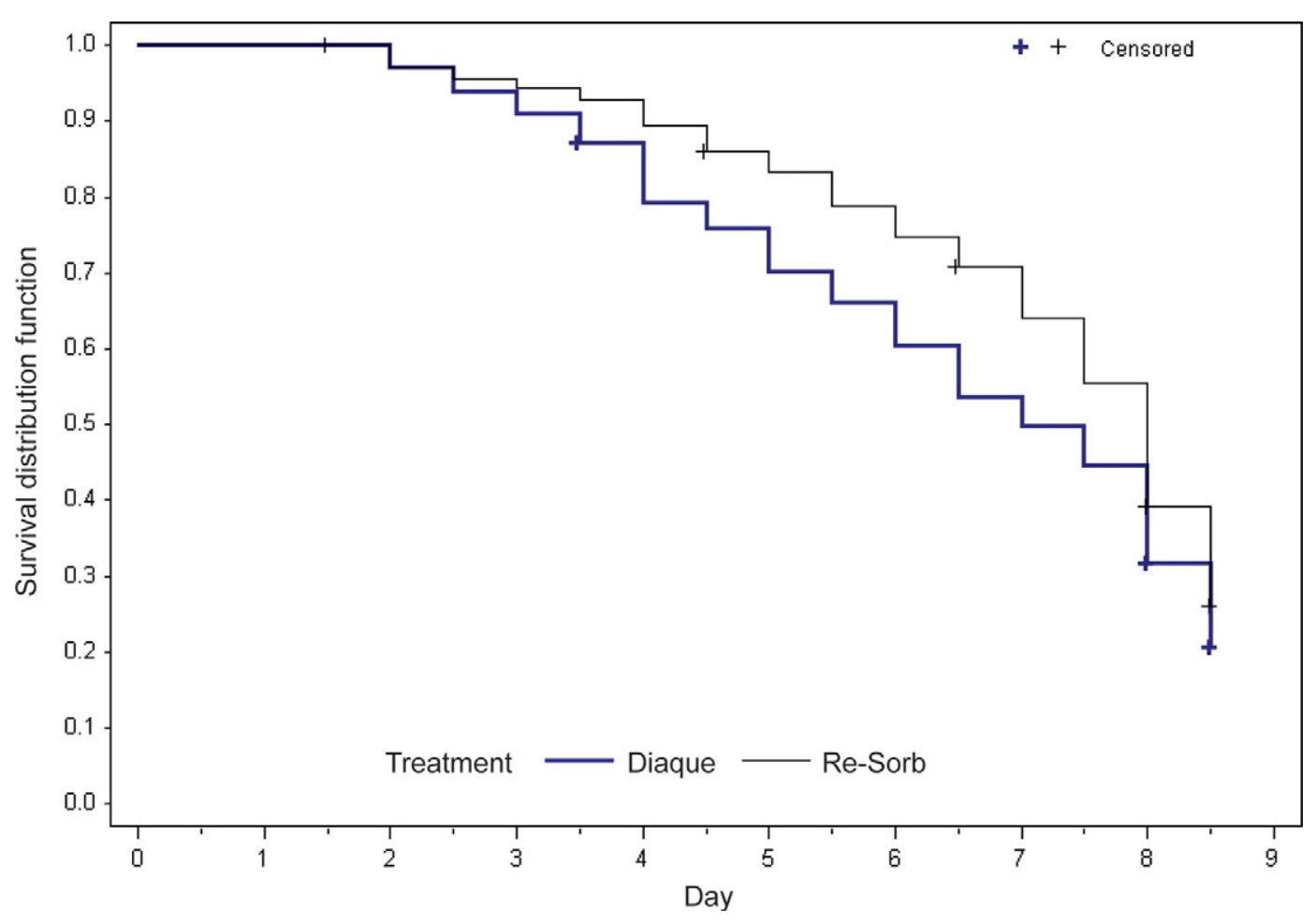

Figure 1. Time-to-event plot showing the change in the proportion of 360 Holstein-Friesian calves with diarrhea over time after diarrhea was first detected. Calves aged between 2 and $30 \mathrm{~d}$ with diarrhea were randomly assigned to be treated with 1 of 2 commercial oral rehydration therapy solutions (Diaque, Boehringer Ingelheim, Ingelheim, Germany; n = 180, group D; RE-SORB, Pfizer Animal Health, New York, NY; $\mathrm{n}$ $=180$, group R) for up to $8 \mathrm{~d}$. Wilcoxon test of equality of strata, $\chi^{2}=6.92, P=0.0085$. Color version available in the online PDF.

\section{Partial Budget Analysis}

At the time the study was conducted, it cost the calf ranch $\$ 2.12 /$ calf per day to raise calves to weaning. This cost included feed, labor (approximately $\$ 12 / \mathrm{h}$ ), and costs associated with all treatments. Milk replacer cost approximately $\$ 59$ per $22.7-\mathrm{kg}$ bag during the study, equivalent to $\$ 0.16 / \mathrm{L}$ when fed at $0.57 \mathrm{~kg} / 1.89 \mathrm{~L}$ $(3.79 \mathrm{~L})$ at $40 \%$ of the total milk mixture.

The estimated median total treatment cost for calves in group D was $\$ 56.70$ for the median $7.0 \mathrm{~d}$ of treatment, comprising $\$ 20.30$ for the ORT (2 treatments/d at $\$ 1.45$ each), $\$ 28.00$ for labor (2 treatments/d at an estimated $10 \mathrm{~min} /$ treatment), and $\$ 8.40$ for milk replacer (total of $26.5 \mathrm{~L}$ of milk solution at $3.79 \mathrm{~L} / \mathrm{d}$ ). For comparison, the estimated median total treatment cost for calves in group $\mathrm{R}$ was $\$ 61.52$ for the median $8.0 \mathrm{~d}$ of treatment, comprising $\$ 25.92$ for the ORT (2 treatments/d at $\$ 1.62$ each), $\$ 32.00$ for labor (2 treatments/d at an estimated $10 \mathrm{~min} /$ treatment), and $\$ 3.60$ for milk replacer (total of $11.36 \mathrm{~L}$ of milk solution at $0 \mathrm{~L} / \mathrm{d}$ for the first $2 \mathrm{~d}$ and $1.89 \mathrm{~L} / \mathrm{d}$ for the following $6 \mathrm{~d}$ of treatment). This partial budget estimate did not attribute a cost to the consumption of pasteurized milk because pasteurization of milk from cows in the hospital pen was considered a fixed cost. Similarly, the partial budget estimate did not attribute a cost to the administration of ceftiofur or activated charcoal for the first $3 \mathrm{~d}$ because this treatment was provided to both groups.

\section{DISCUSSION}

We believe that the study reported here is one of the largest field studies conducted comparing the efficacy of 2 ORT solutions for treating calves with naturally acquired diarrhea. Our major findings were that feeding an ORT solution that contained lecithin-coated citrus fiber in the milk of calves with diarrhea (group D) resulted in a faster return to normal fecal consistency, a larger increase in BW after $4 \mathrm{~d}$ of treatment, and decreased treatment costs, compared with feeding a different ORT solution in conjunction with decreased milk intake (group R). Our findings support recommendations that milk should continue to be fed to calves with diarrhea to maintain growth and facilitate repair of the damaged intestinal epithelium (Heath et al., 1989; Garthwaite et al., 1994).

A statistically significant difference in the days of treatment and a tendency for a difference in ADG in- 


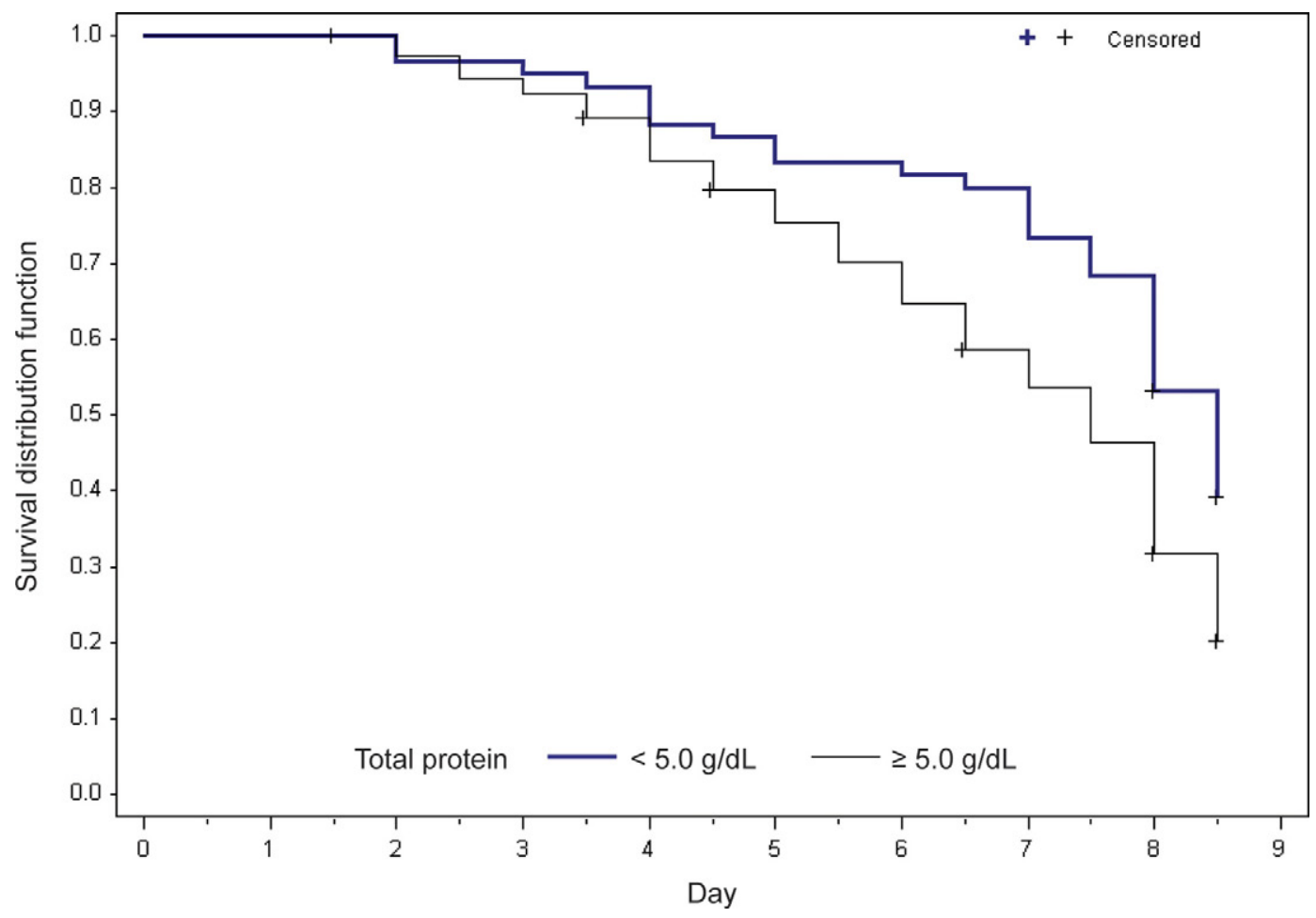

Figure 2. Time-to-event plot showing the change in the proportion of 360 Holstein-Friesian calves with diarrhea over time after diarrhea was first detected. Calves aged between 2 and $30 \mathrm{~d}$ with diarrhea were categorized as having adequate transfer of passive immunity ([total protein] $\geq 5.0 \mathrm{~g} / \mathrm{dL}$ ) or failure of transfer of passive immunity ([total protein] $<5.0 \mathrm{~g} / \mathrm{dL}$ ) on d 2 of life. Calves were randomly assigned to be treated with 1 of 2 commercial oral rehydration therapy solutions (Diaque, Boehringer Ingelheim, Ingelheim, Germany; n = 180, group D; RE-SORB, Pfizer Animal Health, New York, NY; $\mathrm{n}=180$, group R) for up to 8 d. Wilcoxon test of equality of strata, $\chi^{2}=9.96, P=0.0016$. Color version available in the online PDF.

dicated that group D calves responded more favorably to treatment. The reason for this result is most likely related to energy intake, in that calves in group D were fed, on median treatment durations, $15.1 \mathrm{~L}$ more milk mixture than calves in group $\mathrm{R}$; the former group also received extra energy because of the higher glucose content of the ORT-milk solution fed to the calves (Table 1). Glucose was fed at approximately $2.9 \mathrm{~g} / \mathrm{kg}$ for $36 \mathrm{~kg}$ of BW calves, which was within the theoretical upper range for glucose ingestion in suckling calves of 1.0 to $3.6 \mathrm{~g} / \mathrm{kg}$ of BW (Nouri and Constable, 2006). Glucose ingestion rates above the theoretical upper range run the risk of allowing unabsorbed glucose to carry over into the large intestine, where glucose may be fermented to short-chain VFA and thereby exacerbate fecal water loss.

Commercially available ORT solutions can be categorized by their osmolality and alkalinizing ability (Constable et al., 2001; Constable, 2003). In general, ORT solutions are isotonic or hypertonic and alkalinizing or nonalkalinizing, with hypertonic ORT solutions providing greater nutritional support to dehydrated diarrheic calves (Jones et al., 1984; Levy et al., 1990;
Constable et al., 2001). When administered orally to neonatal calves with or without diarrhea, hypertonic ORT solutions have no deleterious effects, particularly in relation to maintaining appropriate hydration status, intestinal osmolality, serum glucose concentration, and abomasal emptying or intestinal flow rate (Levy et al., 1990; Constable et al., 2001, 2009). The osmolarity of the unstirred layer surrounding the villous tip in the mammalian small intestine is 600 to $700 \mathrm{mOsm} / \mathrm{L}$ (Jodal and Lundgren, 1986), suggesting that hypertonic ORT solutions are physiologically more appropriate than isotonic solutions in the proximal small intestine. Relative to isotonic solutions, hypertonic solutions minimize the loss in BW that occurs when healthy calves are deprived of milk (Fettman et al., 1986).

Commercially available ORT solutions can also be categorized according to the amount and nature of an alkalinizing agent as (1) containing bicarbonate as the main alkalinizing agent; (2) containing metabolizable bases such as acetate, propionate, or citrate as the main alkalinizing agents; or (3) not containing an alkalinizing agent (Booth and Naylor, 1987). Most commercially available ORT solutions in the United States use bi- 
carbonate as an alkalinizing agent. Administration of an ORT solution containing a high concentration of bicarbonate $(80 \mathrm{mM})$ reduced weight gains in diarrheic calves, relative to a non-bicarbonate-containing ORT solution; this effect was attributed to interference with normal clot formation in the abomasum of the milk-fed calf (Heath et al., 1989). For comparison, we recently documented that feeding Diaque in cow's milk was alkalinizing and had a minimal effect on in vivo abomasal milk clotting (Constable et al., 2009); the latter result was attributed to the low concentration of bicarbonate $(25 \mathrm{mM})$. Moreover, the results of the study reported here indicate that feeding an ORT solution containing a low concentration of bicarbonate $(25 \mathrm{mM})$ did not reduce weight gain in diarrheic calves relative to feeding a non-bicarbonate-containing ORT solution; in fact, ADG until weaning tended to be higher in calves fed a low concentration of bicarbonate $(25 \mathrm{mM})$.

The 2 ORT solutions used in the study varied in their alkalinizing ability, with calves in group D being fed a solution with an effective strong ion difference more than twice that of calves in group R ( 88 vs. $30 \mathrm{mEq} / \mathrm{L}$ ). The importance of an effective strong ion difference of an ORT solution in treating calves with diarrhea was first identified in 1996 by Stämpfli et al. (Stämpfli et al., 1996) and the effective strong ion difference concept was extended to characterize the alkalinizing ability of intravenous fluids in 2003 (Constable, 2003). Although not specifically examined in the study reported here, the inclusion of an alkalinizing agent in an ORT solution is important to treat systemic strong ion (metabolic) acidosis, which is frequently present in calves with diarrhea (Naylor et al., 1990; Constable at al., 2005; Sen et al., 2009; Smith, 2009; Müller et al., 2012).

Another difference between the 2 ORT solutions investigated in this study was that Diaque contains hydrophobic pectin fibers, which have been shown to absorb pathogenic strains of Escherichia coli and Salmonella enterica in vitro (Bachmann and Larsen, 1989). It is unknown whether the shorter duration of diarrhea in group $\mathrm{D}$ was due to ingestion of additional waste milk or milk replacer mixture (median of $15.1 \mathrm{~L}$ per diarrhea episode), hydrophobic pectin fibers, or other unidentified factors. It is possible that the longer period of milk feeding in calves in group D was responsible for the shortened duration of diarrhea; other investigators have demonstrated that continued milk feeding to calves with diarrhea facilitates repair of the intestinal epithelium (Heath et al., 1989; Garthwaite et al., 1994).

The study was conducted on a calf-rearing facility that appears to reflect typical management practices for raising Holstein-Friesian calves in the United States (USDA, 2010). This is based on an all-cause mortality rate of $6.1 \%$ from $2 \mathrm{~d}$ of life to weaning (US mean,
$7.8 \%$ ), a failure of transfer of passive immunity rate of $24 \%$ (US mean, 21\%), and feeding a blend of pasteurized nonsalable milk and milk replacer (USDA, 2010). However, the mean ADG of 0.51 to $0.55 \mathrm{~kg} / \mathrm{d}$ until weaning was below the US median ADG value of $0.62 \mathrm{~kg} / \mathrm{d}$ (USDA, 2010) and below the ADG goal advocated by some of 0.68 to $0.91 \mathrm{~kg} / \mathrm{d}$. The study was carried out at the calf ranch during a period with higher than usual morbidity because of scours and respiratory disease, and it is possible that calves in all 3 groups had subclinical respiratory disease that affected their performance. It is likely that the feeding of a fixed volume of milk mixture $(1.89 \mathrm{~L} / \mathrm{d})$ for the first $8 \mathrm{wk}$ of life also contributed to the relatively low ADG. The low mortality rate in both treatment groups in this study was not surprising because only calves with simple, uncomplicated diarrhea were enrolled. All deaths except one occurred after the diarrhea event had resolved.

Failure of transfer of passive immunity has been shown to be associated with an increased risk of mortality in dairy calves (Tyler et al., 1998; Berge et al., $2005,2009)$, as well as an increased risk of diarrhea in dairy calves in some (Berge et al., 2009), but not all, studies (Donovan et al., 1998). Although not a surprising finding, we believe that this is the first study to report an association between failure of transfer of passive immunity and an increased duration of diarrhea in dairy calves. The median duration of diarrhea in calves in the study reported here was 7 to $8 \mathrm{~d}$. The duration of diarrhea in neonatal calves with naturally acquired diarrhea has rarely been reported, but diarrhea, dehydration, and inappetence have been reported to continue for 6 to $8 \mathrm{~d}$ in calves with experimentally induced diarrhea (Bywater, 1980; Naylor et al., 1990) or naturally acquired diarrhea (Garthwaite et al., 1994).

\section{ACKNOWLEDGMENTS}

This study was supported by a grant from Boehringer Ingelheim Vetmedica Inc. (Ingelheim, Germany). The authors thank L. Carstensen of Boehringer Ingelheim Vetmedica Inc. for assistance with study development.

\section{REFERENCES}

Bachmann, L., T. Homeier, S. Arlt, M. Brueckner, H. Rawel, C. Deiner, and H. Hartmann. 2009. Influence of different oral rehydration solutions on abomasal conditions and the acid-base status of suckling calves. J. Dairy Sci. 92:1649-1659.

Bachmann, P., and J. L. Larsen. 1989. Development and testing of a new remedy against acute infectious diarrhea in calves (Diakur). Dansk Vet. Tidsskr. 72:1419-1429.

Bellosa, M. L., D. V. Nydam, J. L. Liotta, J. A. Zambriski, T. C. Linden, and D. D. Bowman. 2011. A comparison of fecal percent dry matter and number of Cryptosporidium parvum oocysts shed to observational fecal consistency scoring in dairy calves. J. Parasitol. 97:349-351. 
Berge, A. C. B., T. E. Besser, D. A. Moore, and W. M. Sischo. 2009 Evaluation of the effects of oral colostrum supplementation during the first fourteen days on the health and performance of preweaned calves. J. Dairy Sci. 92:286-295.

Berge, A. C. B., P. Lindeque, D. A. Moore, and W. M. Sischo. 2005. A clinical trial evaluating prophylactic and therapeutic antibiotic use on health and performance of preweaned calves. J. Dairy Sci. 88:2166-2177.

Booth, A. J., and J. M. Naylor. 1987. Correction of metabolic acidosis in diarrheal calves by oral administration of electrolyte solutions with or without bicarbonate. J. Am. Vet. Med. Assoc. 191:62-68.

Busato, A., L. Steiner, S. W. Martin, M. M. Shoukri, and C. Gaillard. 1997. Calf health in cow-calf herds in Switzerland. Prev. Vet. Med. 30:9-22.

Bywater, R. J. 1977. Evaluation of an oral glucose-glycine-electrolyte formulation and amoxicillin for treatment of diarrhea in calves. Am. J. Vet. Res. 38:1983-1987.

Bywater, R. J. 1980. Comparison between milk deprivation and ora rehydration with a glucose-glycine-electrolyte formulation in diarrhoeic and transported calves. Vet. Rec. 107:549-551.

Cerbulis, J., and H. M. Farrell. 1976. Composition of the milks of dairy cattle. II. Ash, calcium, magnesium, and phosphorus. J. Dairy Sci. 59:589-593.

Collett, D. 2003. Modelling Survival Data in Medical Research. 2nd ed. Chapman and Hall/CRC Press LLC, Boca Raton, FL.

Constable, P. D. 2003. Fluids and electrolytes. Clin. Pharmacol. 19:1-40.

Constable, P. D., W. Grünberg, and L. Carstensen. 2009. Comparative effects of two oral rehydration solutions on milk clotting, abomasal luminal $\mathrm{pH}$, and abomasal emptying rate in suckling calves. J. Dairy Sci. 92:296-312.

Constable, P. D., H. R. Stampfli, H. Navetat, J. Berchtold, and F. Schelcher. 2005. Use of a quantitative strong ion approach to determine the mechanism for acid-base abnormalities in diarrheic and sick calves. J. Vet. Intern. Med. 19:581-589.

Constable, P. D., E. Thomas, and B. Boisrame. 2001. Comparison of two oral electrolyte solutions for the treatment of dehydrated calves with experimentally-induced diarrhoea. Vet. J. 162:129 141

Davies, D. T., and J. C. D. White. 1959. The use of ultrafiltration and dialysis in isolating the aqueous phase of milk and in determining the partition of milk constituents between the aqueous and disperse phases. J. Dairy Res. 27:171-190.

Donovan, G. A., I. R. Dohoo, D. M. Montgomery, and F. L. Bennett. 1998. Associations between passive immunity and morbidity and mortality in dairy heifers in Florida, USA. Prev. Vet. Med. 34:31-46.

Fettman, M. J., P. A. Brooks, K. P. Burrows, and R. W. Phllips. 1986. Evaluation of commercial oral replacement formulas in healthy neonatal calves. J. Am. Vet. Med. Assoc. 188:397-401.

Garthwaite, B. D., J. K. Drackley, G. C. McCoy, and E. H. Jaster. 1994. Whole milk and oral rehydration solution for calves with diarrhea of spontaneous origin. J. Dairy Sci. 77:835-843.

Heath, S. E., J. M. Naylor, B. L. Guedo, L. Petrie, C. G. Rousseaux, and O. M. Radostits. 1989. The effects of feeding milk to diarrheic calves supplemented with oral electrolytes. Can. J. Vet. Res. $53: 477-485$.

Jodal, M., and O. Lundgren. 1986. Countercurrent mechanisms in the mammalian gastrointestinal tract. Gastroenterology 91:225-241.
Jones, R., R. W. Phillips, and J. L. Cleek. 1984. Hyperosmotic oral replacement fluid for diarrheic calves. J. Am. Vet. Med. Assoc. 184:1501-1505.

Levy, M., A. M. Merritt, and L. C. Levy. 1990. Comparison of the effects of an isosmolar and hyperosmolar oral rehydrating solution on the hydration status, glycemia and ileal content composition of healthy neonatal calves. Cornell Vet. 80:143-151.

Müller, K. R., A. Gentile, W. Klee, and P. D. Constable. 2012. Importance of the effective strong ion difference of an intravenous solution in the treatment of diarrheic calves with naturally-acquired acidemia and strong ion (metabolic) acidosis. J. Vet. Intern. Med. 26:674-683.

Naylor, J. M., L. Petrie, M. I. Rodriguez, and P. Skilnick. 1990. A comparison of three oral electrolyte solutions in the treatment of diarrheic calves. Can. Vet. J. 31:753-760.

Nouri, M., and P. D. Constable. 2006. Comparison of two oral electrolyte solutions and route of administration on the abomasal emptying rate of Holstein-Friesian calves. J. Vet. Intern. Med. 20:620-626.

Sen, I., V. Altunok, M. Ok, A. Coskun, and P. D. Constable. 2009. Efficacy of oral rehydration therapy solutions containing sodium bicarbonate or sodium acetate for treatment of calves with naturally acquired diarrhea, moderate dehydration, and strong ion acidosis. J. Am. Vet. Med. Assoc. 234:926-934.

Sen, I., P. D. Constable, and T. S. Marshall. 2006. Effect of suckling isotonic or hypertonic solutions of sodium bicarbonate or glucose on abomasal emptying rate in calves. Am. J. Vet. Res. 67:13771384

Smith, G. W. 2009. Treatment of calf diarrhea: Oral fluid therapy. Vet. Clin. North Am. Food Anim. Pract. 25:55-72.

Stämpfli, H. R., J. H. Pringle, and J. H. Lumsden. 1996. Experimental evaluation of a novel oral electrolyte solution in the treatment of natural occurring neonatal calf diarrhoea. Pages 98-101 in Proc. XIXth World Buiatrics Congr., Edinburgh, Scotland, UK. Br. Cattle Assoc., Edinburgh, Scotland, UK.

Svensson, C., K. Lundborg, U. Emanuelson, and S. Olsson. 2003. Morbidity in Swedish dairy calves from birth to 90 days of age an individual calf-level risk factors for infectious diseases. Prev. Vet. Med. 58:179-197.

Tyler, J. W., D. D. Hancock, S. M. Parish, D. E. Rea, T. E. Besser, L. Wilson, D. S. Krytenberg, and S. G. Sandersl. 1996. Evaluation of 3 assays for failure of passive transfer in calves. J. Vet. Intern. Med. 10:304-307.

Tyler, J. W., D. D. Hancock, S. E. Wiksie, S. L. Holler, J. M. Gay, and C. C. Gay. 1998. Use of serum protein concentration to predict mortality in mixed-source dairy replacement heifers. J. Vet. Intern. Med. 12:79-83.

USDA (US Department of Agriculture). 2010. Dairy 2007: Heifer Calf Health and Management Practices on U.S. Dairy Operations, 2007. Publ. 550.0110. USDA, Anim. Plant Health Insp. Serv., Vet. Serv., Cent. Epidemiol. Anim. Health, Fort Collins, CO. Accessed Feb. 18, 2012. http://www.aphis.usda.gov/animal_health/nahms/ dairy/downloads/dairy07/Dairy07_ir_CalfHealth.pdf.

Weigler, B. J., D. W. Hird, W. M. Sischo, J. C. Holmes, C. DanayeElmi, C. W. Palmer, and W. W. Utterback. 1990. Veterinary and nonveterinary costs of disease in 29 California dairies participating in the National Animal Health Monitoring System from 1988 to 1989. J. Am. Vet. Med. Assoc. 196:1945-1949. 